\title{
Paramagnetic Platinum and Oxygen Species on Supported Platinum
}

\author{
J. R. Katzer, ${ }^{* 1}$ G. C. A. Schuit, ${ }^{*}$ and J. H. C. Van Hooff $\dagger$ \\ *Center for Catalytic Science and Technology, and \\ $†$ Technische Hogeschool Eindhoven, The Netherlands
}

Received October 27, 1978; revised January 29, 1979

\begin{abstract}
EPR was used to determine the paramagnetic platinum and oxygen species which are present at various stages in the genesis of a supported platinum catalyst and to determine the effect of the support on the formation of such species. Paramagnetic platinum centers, believed to be due to $\mathrm{Pt}^{3+}$, are formed when $\mathrm{Pt}\left(\mathrm{NH}_{3}\right)_{4}{ }^{+2} / \mathrm{Al}_{2} \mathrm{O}_{3}$ is calcined in $\mathrm{O}_{2}$; for low metal contents a large fraction of the platinum is in the form of these species. Catalysts prepared by the same techniques with $\mathrm{SiO}_{2}$ as a support show no paramagnetic platinum signals. Adsorption of $\mathrm{O}_{2}$ on the $\mathrm{Pt} / \mathrm{Al}_{2} \mathrm{O}_{3}$ catalysts results in the formation of a 3- $g \mathrm{O}_{2}{ }^{-}$signal and a second 2- $g$ signal due to $\mathrm{O}^{-}$and results in a corresponding reduction in the platinum signal. Again $\mathrm{Pt} / \mathrm{SiO}_{2}$ did not show comparable behavior. The results are interpreted in terms of electron transfer to the $\mathrm{Al}_{2} \mathrm{O}_{3}$.
\end{abstract}

\section{INTRODUCTION}

Although there has been a continuous increase in the number of spectroscopic techniques applied to the study of heterogeneous catalysts, no single technique provides sufficiently complete characterization. Combination of as many characterization techniques as appropriate and integration of all of the information obtained can provide a much better understanding of a heterogeneous catalyst, yet adequate catalyst characterization remains a most important need in our understanding of heterogeneous catalysis. Electron paramagnetic resonance (EPR) has been successfully applied to the study of transition metal oxide surfaces $(1-7)$, but only limited EPR results have been reported on "more metallic" systems (8-14). EPR work on supported catalysts has been limited to $\mathrm{O}_{2}$ on $\mathrm{Ag} / \mathrm{SiO}_{2}(8-10), \mathrm{Pd}-\mathrm{Y}$ zeolite (14),

${ }^{1}$ Address correspondence to J. R. Katzer, Department of Chemical Engineering, Center for Catalytic Science and Technology, University of Delaware, Newark, Delaware 19711. and to chlorine-containing $\mathrm{Pt}, \mathrm{Pt}-\mathrm{Ir}$, and Ir catalysts on $\mathrm{Al}_{2} \mathrm{O}_{3}(19)$.

There is an increasing body of evidence that even for metals as noble as platinum chemical interactions with the support may play an important role under many conditions. For example, Katzer et al. (15) have shown from EXAFS studies of supported Pt that there appears to be electron transfer from small $\mathrm{Pt}$ crystallites to alumina which increases with decreasing Pt crystallite size. Boudart and Gallezot (16) have observed no electron transfer from small Pt crystallites to monovalent $Y$ zeolite but have observed electron transfer with multivalent (Ce) Y zeolites. Our EXAFS results as well as those of Lytle (17) show little electron transfer from supported $\mathrm{Pt}$ to silica.

Tauster et al. (18) have reported that $\mathrm{Pt} / \mathrm{TiO}_{2}$ chemisorbs $\mathrm{H}_{2}$ normally after lowtemperature reduction, but after hightemperature reduction it will not chemisorb $\mathrm{H}_{2}$, although the $\mathrm{Pt}$ remains highly dispersed. Den Otter and Dautzenberg (19) 
TABLE 1

Dispersion and Calculated Crystallite Size of Reduced Catalysts

\begin{tabular}{lccc}
\hline Catalyst & $\mathrm{Pt}(\mathrm{wt} \%)$ & $D^{a}$ & $d_{\mathrm{p}}{ }^{b}(\mathrm{~nm})$ \\
\hline $\mathrm{Pt} / \mathrm{Al}_{2} \mathrm{O}_{3}$ & 0.40 & $1.00(1.14)$ & $<1.0$ \\
$\mathrm{Pt} / \mathrm{Al}_{2} \mathrm{O}_{3}$ & 2.90 & 0.84 & 1.2 \\
$\mathrm{Pt} / \mathrm{SiO}_{2}$ & 2.90 & 0.69 & 1.5 \\
\hline
\end{tabular}

${ }^{a} D=$ Dispersion $=$ No. of Pt atoms on surface $/$ total No. of Pt atoms (chemisorption ratio greater than $\mathbf{1 . 0 0}$ as shown in parentheses indicates deviations from $1: 1 \mathrm{Pt}_{\mathrm{S}}: \mathrm{H}$ stoichiometry at very high degrees of dispersion).

${ }^{b}$ Average $\mathrm{Pt}$ crystallite size calculated from $\mathrm{H}_{2}$ chemisorption, based on spherical geometry.

have proposed that with high-temperature $\mathrm{H}_{2}$ reduction of $\mathrm{Pt} / \mathrm{Al}_{2} \mathrm{O}_{3}$ direct alloy type bonding occurs between $\mathrm{Pt}$ and aluminum of the partially reduced $\mathrm{Al}_{2} \mathrm{O}_{3}$. We have shown that the specific catalytic activity of $\mathrm{Pt} / \mathrm{Al}_{2} \mathrm{O}_{3}$ for low-temperature $\mathrm{NH}_{3}$ oxidation decreases by over two orders of magnitude with increasing $\mathrm{Pt}$ dispersion and that highly dispersed $\mathrm{Pt} / \mathrm{SiO}_{2}$ has an order of magnitude higher specific catallytic activity than $\mathrm{Pt} / \mathrm{Al}_{2} \mathrm{O}_{3}$ of similar dispersion (20). The nature of the chemical interaction with the support as indicated by the above examples requires further refinement.

The objectives of this work were to determine the paramagnetic platinum and oxygen species which are present in the various stages in the genesis of a supported platinum catalyst and to determine how the support is involved in the formation of such species.

\section{EXPERIMENTAL METHODS}

The alumina and silica on which the platinum was to be placed was crushed and screened to the 14- to 20-mesh range, washed in $20 \%$ nitric acid for $30 \mathrm{~min}$, rinsed with distilled water, dried, and calcined at $973 \mathrm{~K}$ in air overnight. Platinum in the form of $\mathrm{Pt}\left(\mathrm{NH}_{3}\right)_{4}(\mathrm{OH})_{2}$ was then ion exchanged (adsorbed) onto the alumina and silica. The support was allowed to stand in contact with the exchange solution for 12 days to assure uniform distribution throughout the particles, the water was evaporated at $363 \mathrm{~K}$ over several days, and the samples were dried at $393 \mathrm{~K}$ for 1 day. Samples of $\mathrm{Pt} / \mathrm{Al}_{2} \mathrm{O}_{3}$ and $\mathrm{Pt} / \mathrm{SiO}_{2}$ were prepared containing $2.9 \mathrm{wt} \% \mathrm{Pt}$ and 0.4 wt $\% \mathrm{Pt}$.

The resultant catalysts were typically calcined in flowing oxygen by heating from 323 to $623 \mathrm{~K}$ at $1 \mathrm{~K} / \mathrm{min}$ and then holding at $623 \mathrm{~K}$ for $3 \mathrm{hr}$. For those samples that were reduced, reduction was carried out in flowing $\mathrm{H}_{2}$ by heating from 323 to $623 \mathrm{~K}$ at $1 \mathrm{~K} / \mathrm{min}$ and holding at $623 \mathrm{~K}$ for $3 \mathrm{hr}$. This procedure has been shown to give highly dispersed $\mathrm{Pt}$ in $\mathrm{Y}$ zeolite (12) and on these supports (13). The reduced samples were amorphous to $x$-ray diffraction; dispersions determined by hydrogen chemisorption and calculated $\mathrm{Pt}$ crystallite sizes are given in Table 1 . The $2.9 \mathrm{wt} \%$ $\mathrm{Pt} / \mathrm{Al}_{2} \mathrm{O}_{3}$ was shown by electron microscopy to contain a narrow crystallite size distribu-
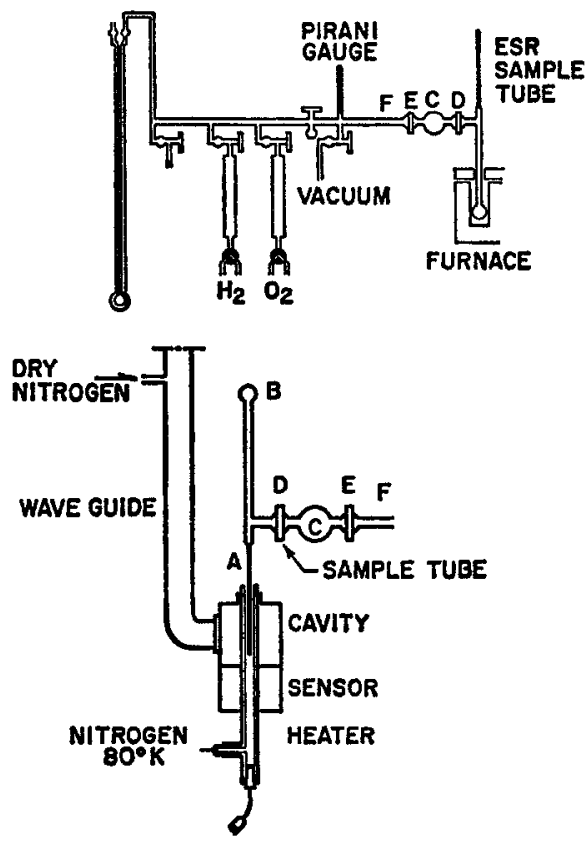

FIG. 1. Vacuum and gas dosing system with sample tube and orientation in EPR spectrometer. 
tion with all $\mathrm{Pt}$ crystallites between 2.0 and $3.2 \mathrm{~nm}$ for over 500 crystallites counted.

Samples of $\mathrm{Pt} / \mathrm{Al}_{2} \mathrm{O}_{3}$ and of $\mathrm{Pt} / \mathrm{SiO}_{2}$ at several stages of pretreatment were introduced into the sample holder with an attached EPR tube (Fig. 1) where further controlled-atmosphere treatments and gas dosing were carried out. The sample could be heated and evacuated in bulb $B$ which promoted effective removal of gases released by the sample. The sample could then be transferred into the 4-mm EPR tube without environmental contact; gas for later dosing could be stored in bulb C. Evacuation was typically to less than $10^{-4}$ Torr during the later stages of heating the sample and after cooling to room temperature.

EPR spectra were taken on an AEG (Model No. 533) spectrometer with an $\mathrm{X}$-band microwave bridge and low-temperature accessory for measurements at temperatures to $77 \mathrm{~K}$. Measurement techniques were standard. Instrument parameters were varied over a broad range to define conditions under which operating parameters adversely affected line shape and intensity, and these operating regions were avoided.

To quantify the EPR spectra, suitable quality spectra were divided into segments, with very fine grids being used where the rate of change of the derivative was large. The data were then integrated using a computerized trapazoidal integration technique. If the absorption curve did not close to zero, a baseline correction technique was applied, and the derivative curve was integrated again. The absorption curve typically closed to better than $\pm 15 \%$ on the first integration and closed almost exactly after application of baseline correction. Curves that did not close well on the first integration and required large baseline corrections were not used. Integration of the absorption curve gave the desired area. A sharp signal superimposed on a much broader signal was observed in the presence of $\mathrm{O}_{2}$; the two lines were not separable in the derivative mode. Integration of the derivative spectra gave a broad absorption peak with a narrower peak superimposed on it. Smooth interpolation of the curve for the broad peak gave the baseline for the narrow peak and permitted accurate determination of its area.

The alumina was high purity $\eta-\mathrm{Al}_{2} \mathrm{O}_{3}$ (Harshaw No. AL-0104) and had a surface area of $\sim 140 \mathrm{~m}^{2} / \mathrm{g}$; the silica was from W. R. Grace, Davison Chemical Division (Grade 59) and had a surface area of $\sim 290 \mathrm{~m}^{2} / \mathrm{g}$. Gases were high purity from Linde. A weak pitch from Varian containing $1 \times 10^{13} \mathrm{spins} / \mathrm{cm}$ was used to determine the concentration of paramagnetic centers in the Pt samples.

\section{RESULTS}

The alumina support had a weak paramagnetic signal with a $g$ value of 4.26 . No other signals appeared either before or after evacuation or upon calcining to $623 \mathrm{~K}$ in $\mathrm{O}_{2}$ using the same procedures used for the Pt-containing samples. Addition of 10-Torr $\mathrm{O}_{2}$ to the calcined, evacuated support sample did not result in any new signals or other changes; neither did heating in $\mathrm{H}_{2}$ to $623 \mathrm{~K}$ or subsequent addition of $\mathrm{O}_{2}$. The silica support also contained a weak signal with an approximate $g$ value of 4.26. The silica did not show any other signals after calcination in $\mathrm{O}_{2}$ or after heating in $\mathrm{H}_{2}$ at $623 \mathrm{~K}$; no new signals appeared upon addition of 10-Torr $\mathrm{O}_{2}$ to either the calcined or reduced $\mathrm{SiO}_{2}$.

For the $\mathrm{Pt} / \mathrm{Al}_{2} \mathrm{O}_{3}$ the majority of the work was done with a sample of $2.9 \mathrm{wt} \%$ $\mathrm{Pt} / \mathrm{Al}_{2} \mathrm{O}_{3}$. The results obtained were confirmed identically on a second sample, and similar results were obtained on a sample of $0.4 \mathrm{wt} \% \mathrm{Pt} / \mathrm{Al}_{2} \mathrm{O}_{3}$. The EPR line with a $g$ value of 4.26 was also present in all $\mathrm{Pt} / \mathrm{Al}_{2} \mathrm{O}_{3}$ and $\mathrm{Pt} / \mathrm{SiO}_{2}$ samples and was independent of pretreatment or adsorption conditions. Since it did not change in in- 


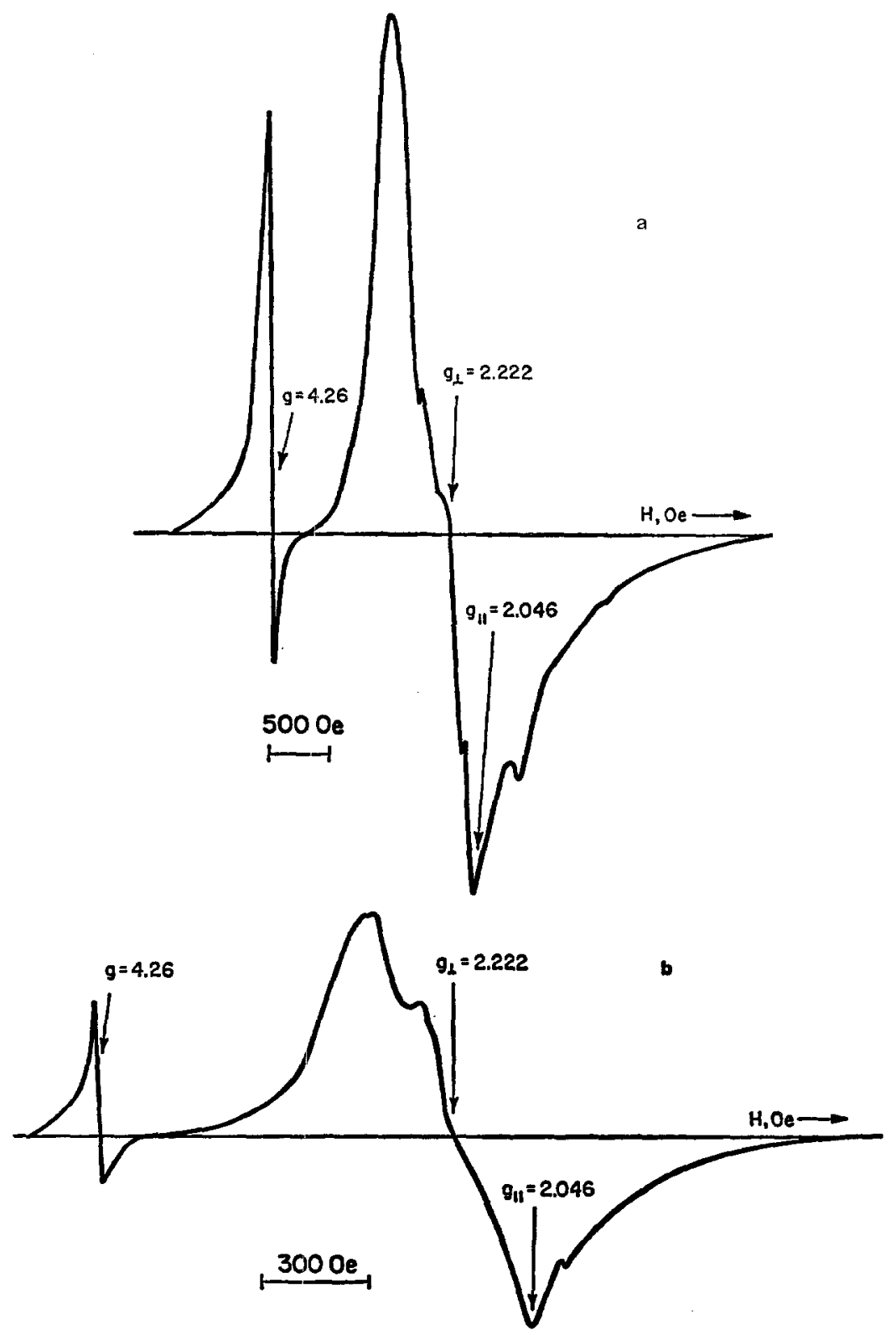

Fig. 2. EPR spectra of $2.9 \mathrm{wt} \% \mathrm{Pt} / \mathrm{Al}_{2} \mathrm{O}_{3}$ after calcination in $\mathrm{O}_{2}$ at $623 \mathrm{~K}$ followed by evacuation to $<10^{-4}$ Torr at $623 \mathrm{~K}$. (a) spectrum taken at $298 \mathrm{~K}$; (b) spectrum taken at $80 \mathrm{~K}$.

tensity, it could be used to gauge the relative peak heights on the spectra prepresented below.

After drying the 2.9 wt $\% \quad \mathrm{Pt} / \mathrm{Al}_{2} \mathrm{O}_{3}$ sample at $393 \mathrm{~K}$ for $3 \mathrm{hr}$ the sample had a very weak signal with a peak-to-peak width $\left(\Delta H_{\mathrm{pp}}\right)$ of $58 \mathrm{Oe}$ and a $g$ value of about 2.01. Evacuation for $0.25 \mathrm{hr}$ at $373 \mathrm{~K}$ resulted in a $70 \%$ increase in the $g=2.01$ signal, but no other changes were observed. Calcining in $\mathrm{O}_{2}$ to $623 \mathrm{~K}$ with evacuation to $<10^{-4}$ Torr at $623 \mathrm{~K}$ as outlined above lead to a very strong, broad EPR signal with a linewidth $\left(\Delta H_{\mathrm{pp}}\right)$ of $750 \mathrm{Oe}$ and a main $g$ value of 2.222 . This signal was about 200 times more intense than any other 
signals previously observed. Figure 2a shows the characteristic shape of this line at $298 \mathrm{~K}$. Cooling to $80 \mathrm{~K}$ resulted in a reduction in the linewidth to about $600 \mathrm{Oe}$ and an increase in the measured signal intensity which followed very well that predicted by the Curie-Weiss law (Fig. 2b). The line with the $g$ value of 2.01 was also present in the $298 \mathrm{~K}$ spectrum although it was very weak. The $g=2.01$ line was not present in all calcined evacuated samples of $\mathrm{Pt} / \mathrm{Al}_{2} \mathrm{O}_{3}$. The main signal $(g=2.222)$ will hereafter be referred to as the platinum signal; this signal has a fine structure, which will be discussed below.

The addition of 10-Torr $\mathrm{O}_{2}$ to the EPR tube resulted in the rapid formation of a new, strong, and more complex EPR signal with a peak-to-peak width $\left(\Delta H_{\mathrm{pp}}\right)$ of about 70 Oe and a $g$ value of 2.010 for the main line (Fig. 3). Associated with the formation of this new line there was a simultaneous, marked reduction in the intensity of the platinum $(g=2.222)$ signal. This new line $(g=2.010)$ will hereafter be referred to as the oxygen signal. Reduction in the oxygen pressure resulted in both a reduction in the intensity of the oxygen signal and a significant increase in the amount of detail visible in the signal (Fig. 4). This fine structure will be discussed below. More complete evacuation to pressures below $10^{-4}$ Torr at room temperature resulted in complete removal of the oxygen signal and return of the platinum signal to its original intensity. Readdition of $\mathrm{O}_{2}$ resulted in reappearance of the oxygen signal, and evacuation removed it again. This cycle was repeated six or seven times and was also repeated several times on other samples with no change in either the resultant oxygen or platinum signals with respect to either their shapes or intensities. Observed changes in signal intensity $(\sim 15-20 \%)$

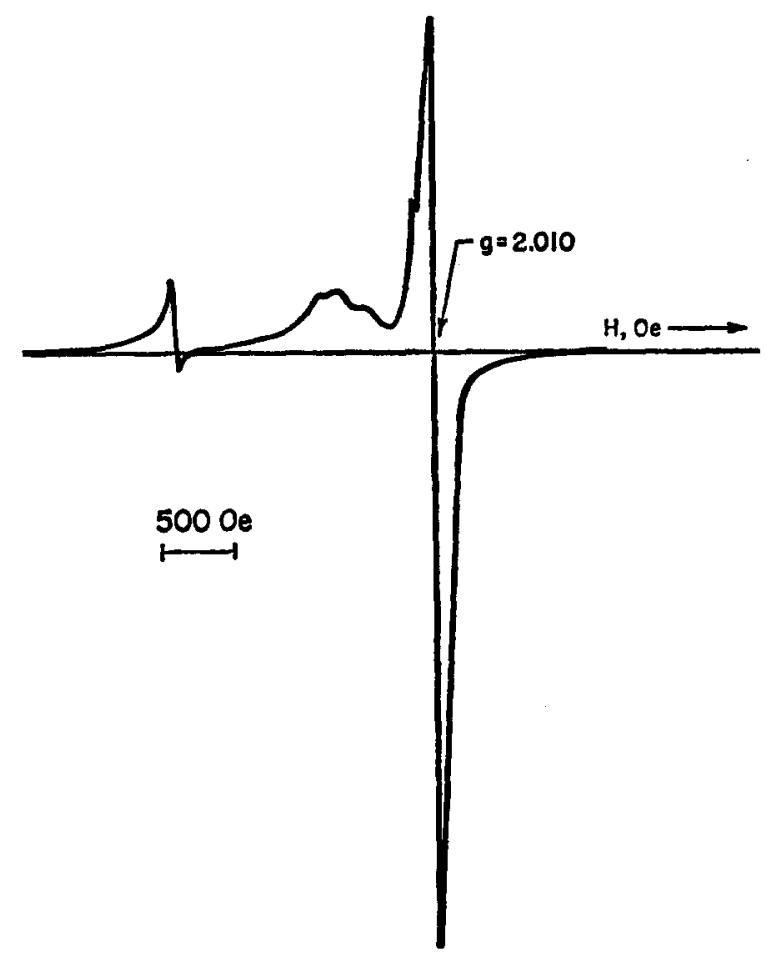

FIG. 3. EPR spectrum obtained at $298 \mathrm{~K}$ upon addition of 10 -Torr $\mathrm{O}_{2}$ to the sample whose spectrum is shown in Fig. 2 

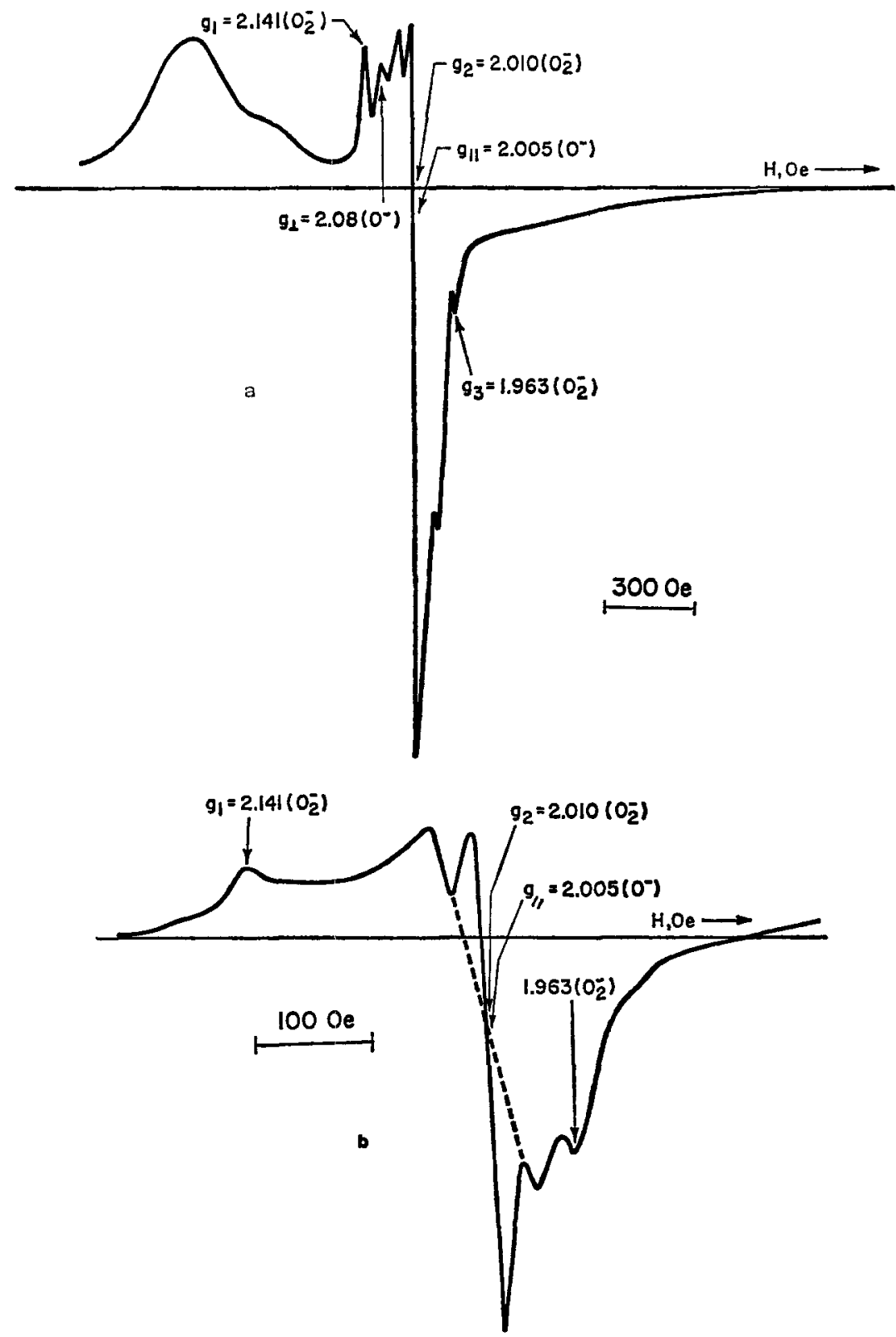

FIg. 4. EPR spectra of $\mathrm{O}_{2}$ adsorbed on calcined, evacuated $\mathrm{Pt} / \mathrm{Al}_{2} \mathrm{O}_{3}$ sample whose spectrum is shown in Fig. 2. Conditions: (a) 0.010-Torr $\mathrm{O}_{2}$, spectrum taken at $298 \mathrm{~K}$; (b) 0.10 -Torr $\mathrm{O}_{2}$, spectrum taken at $80 \mathrm{~K}$.

could be attributed mainly to effects resulting from removing and repositioning the sample tube in the EPR cavity

The presence of four peaks in the EPR spectra of oxygen adsorbed on $2.9 \mathrm{wt} \%$ $\mathrm{Pt} / \mathrm{Al}_{2} \mathrm{O}_{3}$ which had been calcined and evacuated at $623 \mathrm{~K}$ suggests that the oxygen signal is actually composed of two different signals. There is further indication of this in the effect of $\mathrm{O}_{2}$ pressure on the signal. The intensity of the center line of the oxygen signal increased relative to the 
other portions of the signal with decreasing $\mathrm{O}_{2}$ pressure.

Addition of 10 -Torr $\mathrm{O}_{2}$ at $80 \mathrm{~K}$ resulted in only a moderately strong oxygen signal with a relatively weaker line in its center, although the detailed structure was substantially missing due to physically adsorbed oxygen. It is not clear whether the reduced oxygen peak intensity resulted because of the reduced reactivity of $\mathrm{O}_{2}$ at $80 \mathrm{~K}$ and thus its inability to dissociate or because the oxygen was condensed on the porous $\mathrm{Al}_{2} \mathrm{O}_{3}$ in the upper portion of the tube and never reached the $\mathrm{Pt} / \mathrm{Al}_{2} \mathrm{O}_{3}$ in the lower portion of the tube. The oxygen signal intensity relative to the platinum signal intensity was approximately equivalent to that observed for $0.02-$ Torr $\mathrm{O}_{2}$ at $298 \mathrm{~K}$.

At $298 \mathrm{~K}$ with the $\mathrm{O}_{2}$ pressure reduced to 0.10 Torr, 100 -Torr $\mathrm{H}_{2}$ was added to the EPR tube in the spectrometer, and a spectrum was taken immediately thereafter. There was no evidence of any remaining oxygen signal in this spectrum, and the platinum signal had returned to its normal intensity. The adsorbed oxygen species had reacted rapidly with added $\mathrm{H}_{2}$ at room temperature. After evacuation, addition of 10-Torr $\mathrm{O}_{2}$ resulted in the reappearance of the oxygen signal along with reduction in the intensity of the platinum signal. Both the oxygen and platinum signals were significantly more intense $(\sim 25 \%)$ than observed previously; this was probably due to surface changes produced by reaction with $\mathrm{H}_{2}$ since an increase to this level had not been observed in any of the other experiments.

If the relaxation time is rapid relative to the frequency of the microwave radiation the signal intensity will be proportional to the microwave power applied, and the number of spins determined from the peak intensity will be accurate. If saturation of the signal with increasing power occurs, the calculated spin concentration will be in error. Room temperature spectra of the calcined and evacuated $2.9 \mathrm{wt} \% \mathrm{Pt} / \mathrm{Al}_{2} \mathrm{O}_{3}$ and of the sample in the presence of $0.2-$ Torr $\mathrm{O}_{2}$ showed the desired variation in signal intensity with microwave power, indicating lack of saturation effects.

The $0.4 \mathrm{wt} \% \mathrm{Pt} / \mathrm{Al}_{2} \mathrm{O}_{3}$ calcined at $623 \mathrm{~K}$ in $\mathrm{O}_{2}$ and evacuated to $<10^{-4}$ Torr at $623 \mathrm{~K}$ had a platinum signal which had a lineshape equivalent to that observed for the $2.9 \mathrm{wt} \% \mathrm{Pt} / \mathrm{Al}_{2} \mathrm{O}_{3}$ and a peak intensity which was about $70 \%$ of the value for the $2.9 \mathrm{wt} \% \mathrm{Pt} / \mathrm{Al}_{2} \mathrm{O}_{3}$. Thus the number of paramagnetic centers formed appears to be only weakly dependent on the platinum content in the range studied. The number of paramagnetic centers formed may therefore be more a function of sites on the $\mathrm{Al}_{2} \mathrm{O}_{3}$ surface which interact with the platinum. Addition of $\mathrm{O}_{2}$ produced an oxygen signal which had a line shape that was identical to that for $\mathrm{O}_{2}$ on the $2.9 \mathrm{wt} \%$ $\mathrm{Pt} / \mathrm{Al}_{2} \mathrm{O}_{3}$ suggesting that the species formed were the same. The intensity in the presence of 10-Torr $\mathrm{O}_{2}$ was less than that for the $2.9 \mathrm{wt} \% \quad \mathrm{Pt} / \mathrm{Al}_{2} \mathrm{O}_{3}$ suggesting that the paramagnetic platinum centers formed did not pick up $\mathrm{O}_{2}$ as readily.

When the calcined $\mathrm{Pt} / \mathrm{Al}_{2} \mathrm{O}_{3}$ was reduced in flowing $\mathrm{H}_{2}$ at $623 \mathrm{~K}$, the platinum signal was eliminated, but a new, strong symmetric signal of broad linewidth $\left(\Delta H_{\mathrm{pp}}\right.$ $=1420$ Oe) appeared. The intensity of this spectrum was proportional to the metal content of the catalyst, and its linewidth $\left(\Delta H_{\mathrm{pp}}\right)$ was reduced to about 250 Oe by cooling to $80 \mathrm{~K}$. It had an approximate $g$ value of 2.28 . This signal will not be considered further here.

Addition of 10-Torr $\mathrm{O}_{2}$ to the reduced $\mathrm{Pt} / \mathrm{Al}_{2} \mathrm{O}_{3}$ did not result in the formation of of an oxygen signal. Heating the reduced $\mathrm{Pt} / \mathrm{Al}_{2} \mathrm{O}_{3}$ in 50-Torr $\mathrm{O}_{2}$ overnight at $698 \mathrm{~K}$ with subsequent evacuation to $<10^{-4}$ Torr at $623 \mathrm{~K}$ and addition of 10-Torr $\mathrm{O}_{2}$ at $298 \mathrm{~K}$ resulted in the appearance of a weak oxygen signal identical in line shape to that observed for the unreduced, calcined $\mathrm{Pt}$ / $\mathrm{Al}_{2} \mathrm{O}_{3}$ with 10-Torr $\mathrm{O}_{2}$. However, the mag- 
nitude of the oxygen signal on this material was only about $1 \%$ of the magnitude of the oxygen signal for the unreduced, calcined samples.

The sample of $2.9 \mathrm{wt} \% \mathrm{Pt} / \mathrm{SiO}_{2}$ was calcined and evacuated in a manner identical to that for the $\mathrm{Pt} / \mathrm{Al}_{2} \mathrm{O}_{3}$, and EPR spectra were taken. Although a signal appeared to be present, it was very weak, very broad, and very asymmetric, not at all characteristic of the platinum signal observed for $\mathrm{Pt} / \mathrm{Al}_{2} \mathrm{O}_{3}$. The lineshape was only slightly different and only slightly more intense than the spectrum observed for an empty, evacuated quartz EPR tube. Addition of 10-Torr $\mathrm{O}_{2}$ to the calcined, evacuated $\mathrm{Pt} / \mathrm{SiO}_{2}$ sample did not result in a distinguishable oxygen signal or any other significant change in the spectrum, again in marked contrast to the behavior observed upon addition of $\mathrm{O}_{2}$ to calcined, evacuated $\mathrm{Pt} / \mathrm{Al}_{2} \mathrm{O}_{3}$.

Reduction of the $\mathrm{Pt} / \mathrm{SiO}_{2}$ at $623 \mathrm{~K}$ in flowing $\mathrm{H}_{2}$ produced at most a slight reduction of the broad line in the spectrum; the resultant spectrum was essentially that for the empty, evacuated quartz EPR tube. There was no similarity between the EPR spectra for reduced $\mathrm{Pt} / \mathrm{SiO}_{2}$ and $\mathrm{Pt} / \mathrm{Al}_{2} \mathrm{O}_{3}$ although the $\mathrm{Pt}$ crystallite sizes as determined by $\mathrm{H}_{2}$ chemisorption were similar.

When the reduced sample of $\mathrm{Pt} / \mathrm{SiO}_{2}$ was calcined in $\mathrm{O}_{2}$ at $623 \mathrm{~K}$ for $1.5 \mathrm{hr}$ and evacuated to $<10^{-4}$ Torr, there was again a slight increase in the intensity of the broad line, similar to the lineshape of the initially calcined $\mathrm{Pt} / \mathrm{SiO}_{2}$. Addition of 10-Torr $\mathrm{O}_{2}$ to the sample of $\mathrm{Pt} / \mathrm{SiO}_{2}$ which was calcined in $\mathrm{O}_{2}$ after reduction produced a weak and very narrow $\left(\Delta H_{\mathrm{pp}}\right.$ $=11 \mathrm{Oe}$ ) line occurring at about $g=2.01$ which was apparently a $1-g$ signal resulting from an adsorbed oxygen species. This signal was completely eliminated by evacuation for $2 \mathrm{hr}$ at $623 \mathrm{~K}$ with $P<10^{-4}$ Torr. This oxygen signal could be reversibly added and removed and was reduced by about a factor of 2 by reducing the $\mathrm{O}_{2}$ pressure to 0.01 Torr.

\section{DISCUSSION OF RESULTS}

The absorption peak with $g=4.26$ is probably due to impurity iron in the $\mathrm{Al}_{2} \mathrm{O}_{3}$ and the $\mathrm{SiO}_{2}$; this is the $g$ value typically observed for iron in solids (21). The fact that the peak intensity was less than $1 / 100$ that of either the platinum or oxygen signals and that it did not undergo any changes with calcination, reduction, or adsorption of $\mathrm{O}_{2}$ either before or after $\mathrm{Pt}$ addition suggests that it is not responsible for or related to the other signals.

The appearance of the strong line at $g=2.222$ upon calcination and evacuation of the $\mathrm{Pt} / \mathrm{Al}_{2} \mathrm{O}_{3}$ samples suggests that this signal is due to an oxidized $\mathrm{Pt}$ species. The signal is a $2 g$ signal with $g_{\perp}=2.222$ and $g_{11}=2.046$. The fine structure in the spectrum is due to splitting by the isotope of platinum $\left({ }^{195} \mathrm{Pt}\right)$ having a nuclear spin $I=\frac{1}{2}$; this isotope is $34 \%$ abundant. The other isotope, which is $66 \%$ abundant and which has a nuclear spin $I=0$, produces the major adsorption curve. The derivative of the EPR absorption curve is constructed in Fig. 5 by sketching in the summation of the adsorption spectra from the lower portion and represents well the observed lineshape (Fig. 2). The splitting parameters for the signal ( $A_{\perp}$ and $A_{11}$ ) were assumed equal and equivalent to the splitting observed by Geschwind and Remeika (22) for $\mathrm{Pt}$ in $\alpha-\mathrm{Al}_{2} \mathrm{O}_{3}, A=150$ Oe. Sroubek, et al. (2S) reported $A=140$ Oe for $\mathrm{Pt}$ in Nb-doped $\mathrm{BaTiO}_{4}$. The $g_{\perp}$ value obtained in this work agrees well with that reported by Geschwind and Remeika (22) for Pt in corundum (for temperatures greater than $79 \mathrm{~K}$, $g=2.220 \pm 0.001)$. At $4.2 \mathrm{~K}$ the Pt signal had $g$ values of $g_{x}=g_{y}=2.328 \pm 0.004$ and $g_{z}=2.011 \pm 0.006$. Sroubek et al. (2S) reported $g_{\perp}=2.51 \pm 0.02$ and 


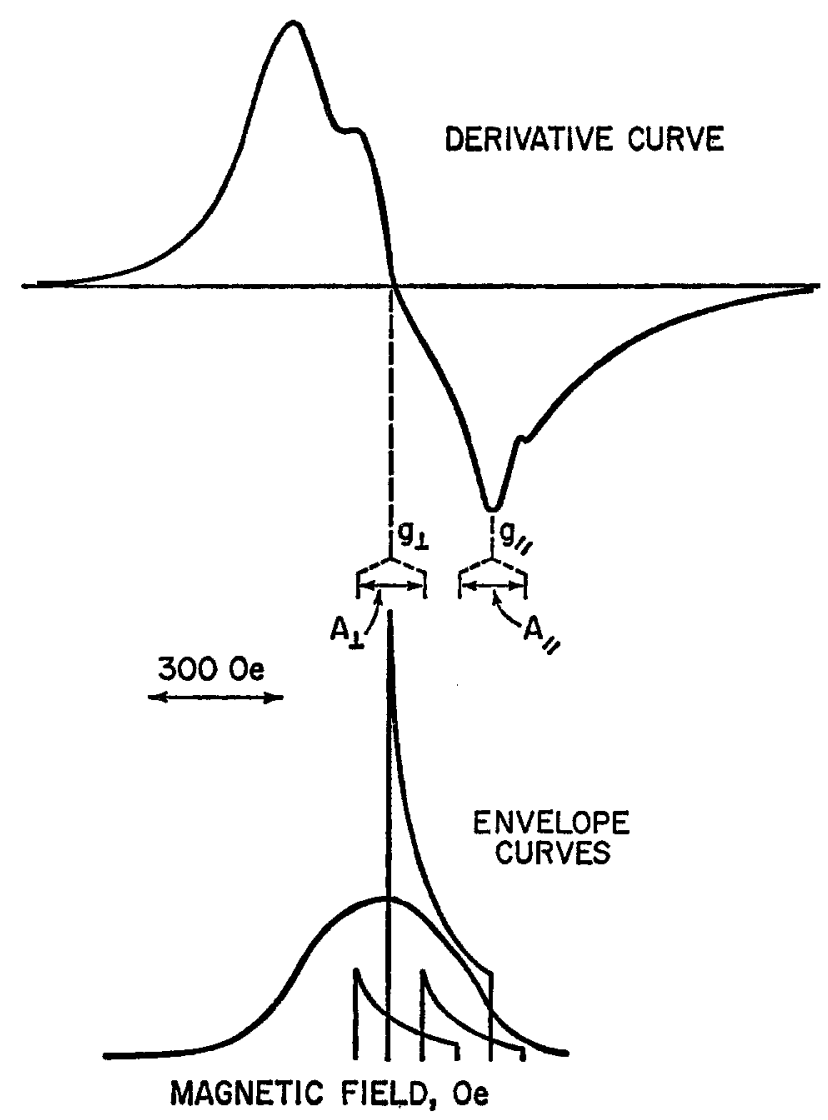

FIG. 5. Constructed paramagnetic platinum spectrum, using known parameters.

$g_{\mathrm{II}}=1.935 \pm 0.005$ for $\mathrm{Pt}^{3+}$ in niobiumdoped $\mathrm{BaTiO}_{3}$.

$\mathrm{Pt}$ in the complex exchanged onto the $\mathrm{Al}_{2} \mathrm{O}_{3}\left(\mathrm{Pt}\left(\mathrm{NH}_{3}\right)_{4}(\mathrm{OH})_{2}\right)$ is $\mathrm{Pt}^{2+}$ which has a $5 d^{8}$ configuration and should give no EPR signal. Calcining should oxidize the $\mathrm{Pt}^{2+}$ to $\mathrm{Pt}^{4+}$; our EXAFS work indicates that this is the case (24). We speculate that the platinum remains highly dispersed, possibly atomically, since the coulombic interactions between the original complex and the $\mathrm{Al}_{2} \mathrm{O}_{3}$ surface remain effective with oxidation. Therefore clusters of platinum oxide are almost certainly absent for the $0.4 \mathrm{wt} \% \mathrm{Pt} / \mathrm{Al}_{2} \mathrm{O}_{3}$ and are probably absent for the $2.9 \mathrm{wt} \% \mathrm{Pt} / \mathrm{Al}_{2} \mathrm{O}_{3}$ although we have no direct evidence for this. Evacuation at $623 \mathrm{~K}$ probably causes a partial reduction of the surface by removing oxygen anions according to :

$$
\mathrm{O}^{2--} \mathrm{Pt}^{4+-} \mathrm{O}^{2-} \rightarrow \square \mathrm{Pt}^{2+}-\mathrm{O}^{2-}+\frac{1}{2} \mathrm{O}_{2} .
$$

Neither $\mathrm{Pt}^{4+}\left(5 \mathrm{~d}^{6}\right)$ nor $\mathrm{Pt}^{2+}\left(5 \mathrm{~d}^{8}\right)$ is paramagnetic. However, if $\square \mathrm{Pt}^{2+}-\mathrm{O}^{2-}$ is in contact with a Lewis acid center on the surface of the calcined $\mathrm{Al}_{2} \mathrm{O}_{3}$, electron transfer to the $\mathrm{Al}_{2} \mathrm{O}_{3}$ could occur,

$$
\begin{gathered}
\square \mathrm{Pt}^{2+-} \mathrm{O}^{2-}+\mathrm{L}-\mathrm{Al}_{2} \mathrm{O}_{3} \rightarrow \\
\square \mathrm{Pt}^{3+}-\mathrm{O}^{2-}+\mathrm{L}^{-}-\mathrm{Al}_{2} \mathrm{O}_{3}, \\
\text { (Lewis acid center) }
\end{gathered}
$$

producing a paramagnetic $\mathrm{Pt}^{3+}\left(5 \mathrm{~d}^{7}\right)$ ion. This would explain the formation of our observed paramagnetic platinum centers. This would also explain the observation that the intensity of the platinum signal was essentially independent of metal con- 
tent. Ion exchange would probably occur at the strong sites first since we allowed 12 days for equilibration. Thus the number of paramagnetic centers formed should be a function of the support and not of metal content as long as sufficient metal is present. This is consistent with the observation that a 7.25 -fold reduction in the $\mathrm{Pt}$ content resulted in only a $30 \%$ reduction in the platinum signal intensity.

It is not readily possible to determine whether the platinum species responsible for the paramagnetic resonance is $\mathrm{Pt}^{1+}$ or $\mathrm{Pt}^{3+}$; this is also the case in the work of Geschwind and Reimeka (22) and of Šroubek et al. (2S). However, the chemistry of the system as outlined above strongly favors $\mathrm{Pt}^{3+}$.

A typical absorption spectrum obtained by integration of a derivative platinum EPR spectrum was quite asymetric due to the 2- $g$ signal. The area of this absorption peak was ratioed to that of the weak pitch sample, which for three scans reproduced to better than $5 \%$, to obtain the number of paramagnetic centers. Table 2 gives the number of paramagnetic centers observed for a series of experiments starting with a freshly calcined, evacuated sample and then consecutively adding and removing oxygen, with spectra being taken after each addition and removal. Reproducibility was quite good. $\mathrm{H}_{2}$ addition and evacuation produced an apparently significant increase in the concentration of paramagnetic centers. The low-temperature determinations are thought to be the most precise. If it is assumed that the average bulk density of the catalyst powder in the EPR tube is $1.0 \mathrm{~g} / \mathrm{cm}^{3}$, the number of Pt atoms per centimeter is about $5 \times 10^{+18}$ for the $2.9 \mathrm{wt} \% \mathrm{Pt} / \mathrm{Al}_{2} \mathrm{O}_{3}$. Therefore, about one out of every 30 platinum atoms is paramagnetic. For the $0.4 \mathrm{wt} \% \mathrm{Pt} / \mathrm{Al}_{2} \mathrm{O}_{3}$ this ratio is about one out of every four platinum atoms. This density of paramagnetic centers is less than one center per $20 \mathrm{~nm}^{2}$ of alumina surface area. This is in the site density range of strong Lewis acid centers on calcined $\mathrm{Al}_{2} \mathrm{O}_{3}$.

The fact that paramagnetic platinum centers were not formed for $2.9 \mathrm{wt} \%$ $\mathrm{Pt} / \mathrm{SiO}_{2}$ when it is calcined and evacuated by the same procedure suggests that the formation of the paramagnetic platinum species involves a specific interaction with the surface of the $\mathrm{Al}_{2} \mathrm{O}_{3}$ and that the interaction is markedly different from that which can occur with $\mathrm{SiO}_{2}$. A probable type of interaction with Lewis acid centers on $\mathrm{Al}_{2} \mathrm{O}_{3}$ has been suggested above; similar Lewis acid centers should not form on $\mathrm{SiO}_{2}$. Electron transfer to $\mathrm{Al}_{2} \mathrm{O}_{3}$ is indicated by our recent EXAFS studies of $\mathrm{Pt} / \mathrm{Al}_{2} \mathrm{O}_{3}$; these results show that highly dispersed clusters of reduced platinum on $\mathrm{Al}_{2} \mathrm{O}_{3}$ are electron deficient suggesting electron transfer to Lewis acid centers (15). We do not see by EXAFS similar electron transfer from $\mathrm{Pt}$ of an equally high degree of dispersion to $\mathrm{SiO}_{2}$ for $\mathrm{Pt} / \mathrm{SiO}_{2}$, consistent with our observed differences between $\mathrm{Pt} / \mathrm{Al}_{2} \mathrm{O}_{3}$ and $\mathrm{Pt} / \mathrm{SiO}_{2}$ in this study. Small $\mathrm{Pt}$ clusters on $\mathrm{Y}$ zeolites do not exhibit electron transfer to the zeolite unless multivalent cations are exchanged into the zeolite (16).

The addition of $\mathrm{O}_{2}$ to these calcined, evacuated samples on $\mathrm{Al}_{2} \mathrm{O}_{3}$ can lead to the formation of $\mathrm{O}_{2}^{-}$species by

$$
\mathrm{Pt}^{3+}-\mathrm{O}^{2-}+\mathrm{O}_{2} \rightarrow \mathrm{O}_{2}^{--}-\mathrm{Pt}^{4+}-\mathrm{O}^{2-} \text {. }
$$

If site pairs are adjacent, $\mathrm{O}^{-}$species could also be formed by:

$$
\begin{array}{r}
\mathrm{O}^{2--} \mathrm{Pt}^{3+} \square+\square \mathrm{Pt}^{3+}-\mathrm{O}^{2-}+\mathrm{O}_{2} \rightarrow \\
\mathrm{O}^{2-}-\mathrm{Pt}^{4+}-\mathrm{O}^{-}+\mathrm{O}^{-}-\mathrm{Pt}^{4+}-\mathrm{O}^{2-}
\end{array}
$$

or

$$
\begin{aligned}
& \mathrm{O}^{2-}-\mathrm{Pt}^{3+} \square+\square \mathrm{Pt}^{2+}-\mathrm{O}^{2-} \rightarrow \\
& \mathrm{O}^{2-}-\mathrm{Pt}^{4+}-\mathrm{O}^{-}+\mathrm{O}^{2-}-\mathrm{Pt}^{4+}-\mathrm{O}^{2-}
\end{aligned}
$$

Reactions (3), (4), and (5) provide a good explanation of the oxygen signal. The complex line that appears upon adsorption of $\mathrm{O}_{2}$ involves one species having a $3-g$ signal and a second species clearly having a 1-g 
signal. The $3-g$ signal is characteristic of the signal observed for $\mathrm{O}_{2}^{-}$species which have been demonstrated to form on many outgassed oxide surfaces $(1-7)$. This could be produced by reaction (3). The $g$ values for the $\mathrm{O}_{2}-$ signal are $g_{1}=2.141, g_{2}=2.010$, and $g_{3}=1.963$. These are in the range observed for other systems $(1-7)$, but values of $g_{1}$ and $g_{3}$ this large and small, respectively, for adsorbed $\mathrm{O}_{2}^{-}$have not been previously reported; further clarification of this signal is desirable.

The second species producing the sharp signal at the center of the oxygen spectrum is inferred to be $\mathrm{O}^{-}$which would be formed by dissociation of $\mathrm{O}_{2}$ in an environment not able to supply four electrons to form $\mathrm{O}^{2-}$, for example, as indicated by Eqs. (4) and/or (5). It is possible that the $\mathrm{O}^{-}$species is associated with $\mathrm{Al}^{3+}$ as proposed by Abdo et al. (25); however, it was reactive with $\mathrm{H}_{2}$ at room temperature. The main $g$ value of this species is 2.005 which is close to values previously reported $(1-3,7,25)$. This species is more tightly bound than $\mathrm{O}_{2}^{-}$(a) as would be expected and (b) as indicated by the fact that the intensity of this signal grows relative to that of the $\mathrm{O}_{2}^{-}$signal with decreasing $\mathrm{O}_{2}$ partial pressure. Similar behavior has been reported for $\mathrm{O}_{2}$ adsorption on outgassed metal oxides $(1,2,7,25)$.

The 3- $g$ signal indicates that there is no axial symmetry in the system for the $\mathrm{O}_{2}{ }^{-}$ species. The large value for $g_{1}$ suggests that the metal ion to which the $\mathrm{O}_{2}-$ is bound has a low change; this would favor $\mathrm{Pt}^{2+}$ rather than $\mathrm{Pt}^{4+}$ as postulated above. The large value would also suggest rather ionic character. Values of $g_{1}$ for $\mathrm{O}_{2}^{-}$adsorbed on an aluminum ion at the surface of $\mathrm{Al}_{2} \mathrm{O}_{3}$ are characteristically 2.034 to $2.038(1,2$, 25-27) establishing that the $\mathrm{O}_{2}^{-}$species observed in this work is not interacting with $\mathrm{Al}^{3+}$ centers on the surface but is interacting with $\mathrm{Pt}$ centers. This is consistent with the observation that the platinum signal intensity decreased in propor- tion to the increase in the oxygen signal intensity. Values of $g_{3}$ for $\mathrm{O}_{2}{ }^{-}$less than 2.003 have been reported $(1,28-30)$.

The signal assigned to $\mathrm{O}^{-}$is possibly a $2-g$ signal with $g_{\perp}$ at about 2.08 ; Fig. $4 \mathrm{a}$ shows a spectrum at low oxygen pressure which would appear to be composed of a 3-g $\mathrm{O}_{2}{ }^{-}$signal and a $2-g \mathrm{O}^{-}$signal. A value of $g_{\perp}=2.042$ has been reported for $\mathrm{O}^{-}$on $\mathrm{MgO}(31,32)$ and $g_{\perp}=2.024$ has been reported for $\mathrm{O}^{-}$on $\mathrm{Al}^{3+}$ (25). Thus the $\mathrm{O}^{-}$ signal appears to also be associated with $\mathrm{Pt}$ and not with the support, consistent with Eqs. (4) and (5). We cannot derive more detailed information from the data about the nature of the paramagnetic oxygen species because the emphasis of the work was not to further quantify this aspect. Additional studies, particularly involving ${ }^{17} \mathrm{O}$, would be useful.

Reactions (3), (4), and (5) indicate that for every $\mathrm{O}_{2}^{-}$or $\mathrm{O}^{-}$species formed one $\mathrm{Pt}^{3+}$ should be converted to $\mathrm{Pt}^{4+}$. There should therefore be a corresponding reduction in the intensity of the platinum signal; such an intensity reduction was observed. The $\mathrm{O}_{2}-$ plus $\mathrm{O}^{-}$peak intensities, obtained by integrating the oxygen absorption peak on top of the platinum absorption peak, were converted into a number of paramagnetic oxygen centers by ratioing the oxygen absorption signal area to that of the weak pitch. Table 2 summarizes the values obtained for the experiments involving adsorbed oxygen for the same series of experiments summarized in the upper portions of the table for zero $\mathrm{O}_{2}$ pressure. The precision is not as good as for the platinum signal alone because of the greater complexity of the spectra and the greater height and narrowness of the oxygen EPR signal. This reduces the platinum signal height as read out on the chart because of the change in the amplification required to accommodate the oxygen signal and thus reduces the precision of the platinum signal. Taking the best values from the table the average concentration of para- 
TABLE 2

Concentration of Paramagnetic Centers for Supported Platinum Catalysts ${ }^{a}$

\begin{tabular}{|c|c|c|c|c|}
\hline Sample & $\begin{array}{l}\mathrm{O}_{2} \text { pressure } \\
\text { (Torr) }\end{array}$ & $\begin{array}{c}\text { Measurement } \\
\text { temperature } \\
\left({ }^{\circ} \mathrm{K}\right)\end{array}$ & $\begin{array}{l}\text { Number of } \\
\text { platinum centers } \\
\text { per gram } \\
\left(\times 10^{-18}\right)\end{array}$ & $\begin{array}{l}\text { Number of } \\
\text { oxygen centers } \\
\text { per gram } \\
\left(\times 10^{-18}\right)\end{array}$ \\
\hline \multicolumn{5}{|l|}{2.9 wt $\%$} \\
\hline $\mathrm{Pt} / \mathrm{Al}_{2} \mathrm{O}_{3}$ & 0 & 298 & 1.8 & - \\
\hline \multicolumn{5}{|l|}{$2.9 \mathrm{wt} \%$} \\
\hline $\mathrm{Pt} / \mathrm{Al}_{2} \mathrm{O}_{3}$ & 0 & 298 & $2.3^{b}$ & - \\
\hline \multicolumn{5}{|l|}{$2.9 \mathrm{wt} \%$} \\
\hline $\mathrm{Pt} / \mathrm{Al}_{2} \mathrm{O}_{3}$ & 0 & 298 & $3.1^{c}$ & - \\
\hline \multicolumn{5}{|l|}{2.9 wt $\%$} \\
\hline $\mathrm{Pt} / \mathrm{Al}_{2} \mathrm{O}_{3}$ & 0 & 80 & 2.3 & - \\
\hline \multicolumn{5}{|l|}{$2.9 \mathrm{wt} \%$} \\
\hline $\mathrm{Pt} / \mathrm{Al}_{2} \mathrm{O}_{3}$ & 0 & 80 & 2.4 & - \\
\hline \multicolumn{5}{|l|}{$2.9 \mathrm{wt} \%$} \\
\hline \multirow[t]{3}{*}{$\mathrm{Pt} / \mathrm{Al}_{2} \mathrm{O}_{3}$} & 10 & 298 & $0.64^{d}$ & $0.80^{d}$ \\
\hline & & & & $(0.78)^{e}$ \\
\hline & & & & {$[0.57]^{f}$} \\
\hline \multicolumn{5}{|l|}{2.9 wt\% } \\
\hline \multirow[t]{3}{*}{$\mathrm{Pt} / \mathrm{Al}_{2} \mathrm{O}_{3}$} & 10 & 298 & 1.1 & 0.48 \\
\hline & & & & $(0.57)$ \\
\hline & & & & {$[0.30]$} \\
\hline \multicolumn{5}{|l|}{$2.9 \mathrm{wt} \%$} \\
\hline \multirow[t]{3}{*}{$\mathrm{Pt} / \mathrm{Al}_{2} \mathrm{O}_{3}$} & 10 & 298 & 1.2 & 0.75 \\
\hline & & & & $(0.61)$ \\
\hline & & & & {$[0.39]$} \\
\hline \multicolumn{5}{|l|}{$2.9 \mathrm{wt} \%$} \\
\hline \multirow[t]{2}{*}{$\mathrm{Pt} / \mathrm{Al}_{2} \mathrm{O}_{3}$} & 10 & 298 & $2.12^{d}$ & 1.3 \\
\hline & & & & {$[0.37]$} \\
\hline \multicolumn{5}{|l|}{$2.9 \mathrm{wt} \%$} \\
\hline \multirow[t]{2}{*}{$\mathrm{Pt} / \mathrm{Al}_{2} \mathrm{O}_{3}$} & 10 & 80 & 1.0 & 0.32 \\
\hline & & & & {$[0.15]^{g}$} \\
\hline \multicolumn{5}{|l|}{$2.9 \mathrm{wt} \%$} \\
\hline \multirow[t]{2}{*}{$\mathrm{Pt} / \mathrm{Al}_{2} \mathrm{O}_{3}$} & 0.01 & 298 & 1.4 & 0.17 \\
\hline & & & & {$[0.089]$} \\
\hline \multicolumn{5}{|l|}{0.4 wt $\%$} \\
\hline $\mathrm{Pt} / \mathrm{Al}_{2} \mathrm{O}_{3}$ & Low & 298 & 1.0 & 0.06 \\
\hline \multicolumn{5}{|l|}{2.9 wt $\%$} \\
\hline $\mathrm{Pt} / \mathrm{SiO}_{2}$ & 10 & 298 & - & 0.02 \\
\hline
\end{tabular}

${ }^{a}$ Concentration of paramagnetic centers was obtained by double integrating the EPR derivative spectra, rationing the area, adjusted to consistent operating parameters, to that for a weak pitch sample containing $1 \times 10^{13} \mathrm{spins} / \mathrm{cm}$ of sample measured at 298 and at $80 \mathrm{~K}$, and assuming that the catalyst density in the EPR tube was $1 \mathrm{~g} / \mathrm{cm}^{3}$. For spectra containing both an oxygen and a platinum signal the entire line was doubly integrated to give the entire absorption area; interpolation of the platinum peak to form a baseline for the oxygen peak allowed the oxygen peak area to be obtained.

${ }^{b}$ After addition of $100-$ Torr $\mathrm{H}_{2}$.

${ }^{c}$ Sample after addition of $100-$ Torr $\mathrm{H}_{2}$ and evacuation.

${ }^{d}$ Indicated numbers are probably not as precise because the signal peaks which were integrated were small.

e Numbers in parentheses were obtained by double integration of only the derivative oxygen signal; since the oxygen signal also contains the negative portion of the platinum signal which could not be subtracted, it will contain a small but significant error.

$f$ Numbers in brackets are the ratios of the oxygen absorption area to the total absorption area.

${ }^{a} \mathrm{O}_{2}$ adsorption at $80 \mathrm{~K}$; oxygen signal much weaker than after adsorption at $298 \mathrm{~K}$. 
magnetic platinum centers if $1.2 \times 10^{18} / \mathrm{g}$, and the average concentration of paramagnetic oxygen centers if $0.64 \times 10^{18} / \mathrm{g}$. The average total number of paramagnetic centers in the presence of $10-$ Torr $\mathrm{O}_{2}$ was $1.8 \times 10^{18} / \mathrm{g}$. This is about $25 \%$ below the total number of paramagnetic platinum centers before oxygen addition. According to reactions (3), (4), and (5) for each paramagnetic oxygen species formed a paramagnetic platinum center should be eliminated. This behavior is approximately observed, supporting reactions (3), (4), and (5) as probable ones. It is also possible that a reaction such as

$$
\begin{aligned}
& \mathrm{O}^{2-}-\mathrm{Pt}^{4+}-\mathrm{O}^{-}+\mathrm{L}^{-}-\mathrm{Al}_{2} \mathrm{O}_{3} \rightarrow \\
& \mathrm{O}^{2-}-\mathrm{Pt}^{4+}-\mathrm{O}^{2-}+\mathrm{L}-\mathrm{Al}_{2} \mathrm{O}_{3}
\end{aligned}
$$

could occur during or following oxygen adsorption resulting in a reduction in the total number of paramagnetic (platinum plus oxygen) centers. The observed reduction in total number of paramagnetic centers could be explained by this type of reaction or could be due to experimental causes; we favor causes such as Eq. (6) over experimental causes. From the ratio of the total number of paramagnetic platinum centers plus oxygen centers (assumed to be the total number of paramagnetic platinum centers initially available) to the number of paramagnetic oxygen centers, about 30 to $35 \%$ of the paramagnetic platinum atoms adsorb oxygen forming paramagnetic oxygen species. The remaining paramagnetic platinum centers are not available, possibly due to steric reasons; some may be located in the near-surface region of the $\mathrm{Al}_{2} \mathrm{O}_{3}$.

The calcined 0.4 wt $\% \quad \mathrm{Pt} / \mathrm{Al}_{2} \mathrm{O}_{3}$ behaved in the same manner and was not studied further.

In the presence of $\mathrm{O}_{2}$ the $\mathrm{Al}_{2} \mathrm{O}_{3}$ again plays a vital role in the surface chemistry of the calcined catalyst. The $2.9 \mathrm{wt} \%$ $\mathrm{Pt} / \mathrm{SiO}_{2}$ after the same calcination and evacuation procedure formed no paramagnetic oxygen centers in the presence of 10-Torr $\mathrm{O}_{2}$. This is consistent with the absence of a measurable concentration of paramagnetic platinum species for the calcined $\mathrm{Pt} / \mathrm{SiO}_{2}$.

Although there may have been little clustering induced by calcination, reduction results in marked clustering and the formation of small metal crystallites. These small crystallites of reduced $\mathrm{Pt}$ atoms can readily adsorb oxygen as demonstrated by oxygen chemisorption and the oxygenhydrogen titration $(39,34)$. Reduced metal atoms readily dissociate oxygen molecules forming largely covalently chemisorbed species or $\mathrm{O}^{2-}$ ions. Thus $\mathrm{O}_{2}^{-}$or $\mathrm{O}^{-}$formation is not expected on reduced platinum surfaces and was not found. Clarkson and Cirillo $(8,9)$ have reported the formation of $\mathrm{O}_{2}{ }^{-}$species on silver supported on quartz; yet Abou-Kais et al. (10) could not find paramagnetic oxygen species on silver supported on silica.

Limited studies on the effect of reoxidation showed that for $\mathrm{Pt} / \mathrm{Al}_{2} \mathrm{O}_{3}$ the procedure used resulted in regeneration of limited capability to form paramagnetic oxygen species upon $\mathrm{O}_{2}$ adsorption on the catalyst after evauation at $623 \mathrm{~K}$. We speculate that appropriate reoxidation procedures could lead to recovery of a much larger fraction of the capability for formation of paramagnetic oxygen species.

For $\mathrm{Pt} / \mathrm{SiO}_{2}$, which did not form a measurable concentration of paramagnetic oxygen species after the original calcination and evacuation, a small concentration (Table 2) of paramagnetic oxygen species, presumably $\mathrm{O}^{-}$, was formed when the reduced sample was reoxidized and evacuated followed by addition of 10-Torr $\mathrm{O}_{2}$. There was no evidence for the formation of $\mathrm{O}_{2}{ }^{-}$species suggesting that in this case the platinum surface on which the paramagnetic oxygen species formed was a partially oxidized platinum crystallite which could provide a sufficiently high concentration of semireduced platinum atoms for reactions (4) and (5) to occur.

Reduction of $\mathrm{Pt} / \mathrm{Al}_{2} \mathrm{O}_{3}$ replaced the paramagnetic platinum signal discussed 
above with an intense, broad, symmetrical absorption line having approximately $g=2.28$. This peak narrowed markedly at lower temperature $(80 \mathrm{~K})$ but was not studied further. The support again plays a primary role in the behavior observed. The reduced $2.9 \mathrm{wt} \% \mathrm{Pt} / \mathrm{SiO}_{2}$ displayed no similar signal although the Pt crystallites formed with $\mathrm{SiO}_{2}$ were similar in size to those formed with $\mathrm{Al}_{2} \mathrm{O}_{3}$ (Table 1 ). If the signal for reduced $\mathrm{Pt} / \mathrm{Al}_{2} \mathrm{O}_{3}$ were due to odd electron effects as has recently been observed and discussed (35-38), then a similar signal should have been observed for $\mathrm{Pt} / \mathrm{SiO}_{2}$ since it had roughly the same Pt crystallite size (Table 1 ). Thus it can be concluded that the EPR signal observed for reduced $\mathrm{Pt} / \mathrm{Al}_{2} \mathrm{O}_{3}$ is due to a direct involvement of platinum with the $\mathrm{Al}_{2} \mathrm{O}_{3}$; we have not studied this behavior sufficiently to speculate on its origin.

These results clearly show the extent and importance of interactions between platinum and alumina as compared to the platinum-silica system and point to the need to consider much more carefully the role of the support in the catalytic system even for a metal as noble as platinum. They also show that the chemistry of preparation and pretreatment can be quite important and probably plays a key role in determining the nature of the final catalyst; understanding the chemistry of the preparation and pretreatment of the catalyst should provide for a better understanding of the final catalyst.

\section{ACKNOWLEDGMENTS}

The measurements were made at the Technische Hogeschool Eindhoven. Financial support for travel and subsistence for JRK was supplied by N.A.T.O. under Research Grant No. 695 and is gratefully acknowledged.

\section{REFERENCES}

1. Lunsford, J. H., Advan. Catal. 22, 265 (1975).

2. Derouane, E. G., and Vedrine, J. C., Ind. Chim. Belg. 38, 375 (1973).
3. Shvets, V. A., and Kazansky, V. B., J. Catal. 25, 123 (1972).

4. Lunsford, J. H., Zingery, L. W., and Rosynek, M. P., J. Catal. 38, 179 (1975).

5. Bielanski, A., and Najbar, M., J. Catal. 25, 398 (1972).

6. Hoang, van can, Ghorbel, A., and Teichner, S. J., Bull. Soc. Chim. Fr. (2), 437 (1972).

7. Van Hooff, J. H. C., "Formation of SurfacePeroxo Compounds" Ph.D. Thesis, Technische Hogeschool Eindhoven, Eindhoven, The Netherlands, 1968.

8. Clarkson, R. B., and Cirillo, A., Jr., J. Vac. Sci. Technol. 9, 1073 (1972).

9. Clarkson, R. B., and Cirillo, A., Jr., J. Catal. 33, 392 (1974).

10. Abdou-Kais, A., Jarjoui, M., Vedrine, J. C., and Gravelle, P. C., J. Catal. 47, 399 (1977).

11. Taupin, C., and Charvolin, J., in "Colloque Ampere XIV," p. 486 (Session 11, No. 8). North-Holland, Amsterdam, 1967.

12. Feher, G., and Kip, A. V., Phys. Rev. 98 (2), 337 (1955).

13. Sivasankar, S., Ramaswamy, A. V., and Ratnasamy, P., J. Catal. 46, 420 (1977).

14. Naccache, C., Primet, M., and Mathieu, M. V., in "Proceedings of the Third International Conference on Molecular Sieves," Advances in Chemistry Series, No. 121, p. 266. American Chemical Society, Washington, D.C., 1973.

15. Katzer, J. R., Lorntson, J., Fukushima, T., and Schultz, J. M., submitted.

16. Boudart, M., and Gallezot, P., personal communication, 1978 ; paper presented at Spring Symposium at the Philadelphia Catalysis Club, May, 1978; paper presented at Roermond Conference on Catalysis, Roermond, The Netherlands, 1978.

17. Lytle, F., personal communication, 1978.

18. Tauster, S. J., Fung, S. C., and Garten, R. J., J. Amer. Chem. Soc. 100, 170 (1978).

19. Den Otter, G. J., and Dautzenberg, F. M., J. Calal. 53, 116 (1978).

20. Krug, S. M., M. Ch. E. thesis, Department of Chemical Engineering, University of Delaware, Newark, Delaware, 1974.

21. Carnevale, et al., J. Noncrystalline Solids 22, 269 (1976).

22. Geschwind, S., and Remeika, J. P., J. Appl. Phys., Supplement to Vol. 33 (1), 370 (1962).

29. Šroubek, Z., Ždànskỳ, K., and Simànek, E., Phys. Status Solidi 3, K-1 (1963).

24. Fukushima, T., and Katzer, J. R., submitted.

25. Abdo, S., Howe, R. F., and Hall, W. K., J. Phys. Chem. 82, 969 (1978). 
26. Gezalov, A. A., Zhabrova, G. M., Nikishia, V. V., Parasky, G. B., and Spiridonov, K. N., Kin. Katal. 9, 462 (1968).

27. Wang, K. M., and Lunsford, J. H., J. Phys. Chem. 73, 2069 (1969) ; 73, 1165 (1971).

28. Bennett, J. E., Ingram, D. J. E., and Schonland, D., Proc. Phys. Soc. Ser. A 69, 556 (1956).

29. Kanzig, W., and Cohen, M. H., Phys. Rev. Lett. 3, 509 (1959).

30. Vedrine, J. C., and Naccache, C., J. Phys. Chem. 77, 1606 (1973).

31. Williamson, W. B., Lunsford, J. H., and Naccache, C., Chem. Phys. Lett. 9 , 33 (1971).
32. Wong, N. B., and Lunsford, J. H., J. Chem. Phys. 55, 3007 (1971).

33. Benson, J. E., and Boudart, M., J. Catal. 4, 704 (1965).

94. Wilson, G. R., and Hall, W. K., J. Calal. 17, 190 (1970).

35. Kubo, R., J. Phys. Soc. Japan 17, 975 (1962).

36. Gorkov, L. P., and Eliashberg, G. M., Sov. Phys. JETP 21, 940 (1965).

37. Kawabata, A., J. Phys. Soc. Japan 29, 902 (1970).

38. Elliott, R. J., Phys. Rev. 96, 266 (1954). 